\title{
Modeling of the kinetics of linear and crosslinking photopolymerizations"'). Part I
}

\author{
Life is Short, Art Long, Opportunity \\ Fleeting, Experimental Slippery, \\ Judgement Difficult.
}

Hippocrates

\begin{abstract}
Summary - A review with 100 references covering the kinetics of photoinitiation by $\alpha$-cleavage photoinitiators, photoinitiation by photoinitiators acting as direct hydrogen atom transfer agents and through photoinduced electron/proton transfer (EPT) mechanism, the kinetics of propagation, termination by trapping radicals in crosslinked networks, termination of polymerization by oxygen.

Key words: photopolymerization, photoinitiators, kinetics of termination and propagation.
\end{abstract}

Free radical linear photopolymerization of monofunctional monomers produces a linear polymer with a different molecular weight distribution (MWD), whereas photopolymerization of multifunctional monomers produces crosslinked complex networks. The crosslinking photopolymerization (photocuring) deviates to a greater or lesser extent from the kinetics of linear photopolymerization of monofunctional monomers, because some assumptions underlying the kinetic scheme of linear polymerization are not valid, and because the crosslinking polymerization conditions are different. The analysis of crosslinking photopolymerization is complicated by the influence of physical properties of the reacting system on the kinetic parameters that control the polymerization behavior. Both linear and crosslinking photopolymerizations are "chain-growth" polymerizations, because their mechanisms comprise chains of kinetic events: initiation, propagation and termination steps. The initiation of polymerization can be different, whereas propagation and termination steps for a given monomer are almost the same.

This paper sets out to compare the kinetics of linear and crosslinking polymerizations, deviations and kinetics modeling. Various details of the individual reactions in the kinetic sequence are discussed individually.

*) Jagiellonian University, Department of Chemistry, Ingardena 3, 30-060 Cracow, Poland. To whom all correspondence should be addressed

**) Polymer Reasearch Group, Department of Dental Biomaterial Science, Karolinska Institute (Royal Academy of Medicine), Box 4064, 14104 Huddinge (Stockholm), Sweden.

***) Paper partially presented at the PTChem Congress, Rzeszów (Poland), September 1999.
Fine reviews and books on different types of photoinitiators and mechanisms of photoinitiation [1-14] and kinetics of polymerizations have been published elsewhere $[1,4,9,11,15,16]$.

\section{PHOTOINITIATION STEP BY $\alpha$-CLEAVAGE PHOTOINITIATORS}

$\alpha$-Cleavage photoinitiators (I) under UV/visible radiation photodecompose to yield two primary radicals $\left(\mathrm{R}_{1}^{*}, \mathrm{R}_{2}^{*}\right)$ :

$$
\mathrm{I} \stackrel{k_{d}, \mathrm{hiv}}{\longrightarrow} \mathrm{R}_{1}^{*}+\mathrm{R}_{2}^{\text {; }}
$$

where: $k_{l l}\left[s^{-1}\right]$ is the rate constant of photoinitiator photodecomposition (photocleavage).

Reaction (1) is a unimolecular photodecomposition with $k_{d}$ as the first-order rate constant of the magnitude of $10^{-4}-10^{-6} \mathrm{~s}^{-1}$.

Photodecomposition of photoinitiators with symmetric structures gives two identical radicals $\left(\mathrm{R}^{\circ}=\mathrm{R}_{1}^{*}=\mathrm{R}_{2}^{*}\right.$ ) which have the same reactivities, e.g. biacetyl [1]:

$$
\mathrm{CH}_{3} \mathrm{CO}-\mathrm{COCH}_{3} \stackrel{1 w}{\longrightarrow} 2 \mathrm{CH}_{3} \mathrm{CO}^{\circ}
$$

or dicumyl peroxide [17]:

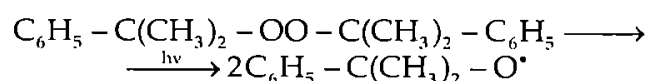

whereas photolysis of photoinitiators with asymmetric structures, like $\alpha$-aminoalkylphenone (Irgacure 369, Ciba) $[18,19]$ (eqn. 4), or acylphosphine oxides (Lucirin TPO, BASF) [19-21] (eqn. 5) gives two different radicals $\left(R_{1}^{*} \neq R_{2}^{*}\right)$, differing in reactivity. 


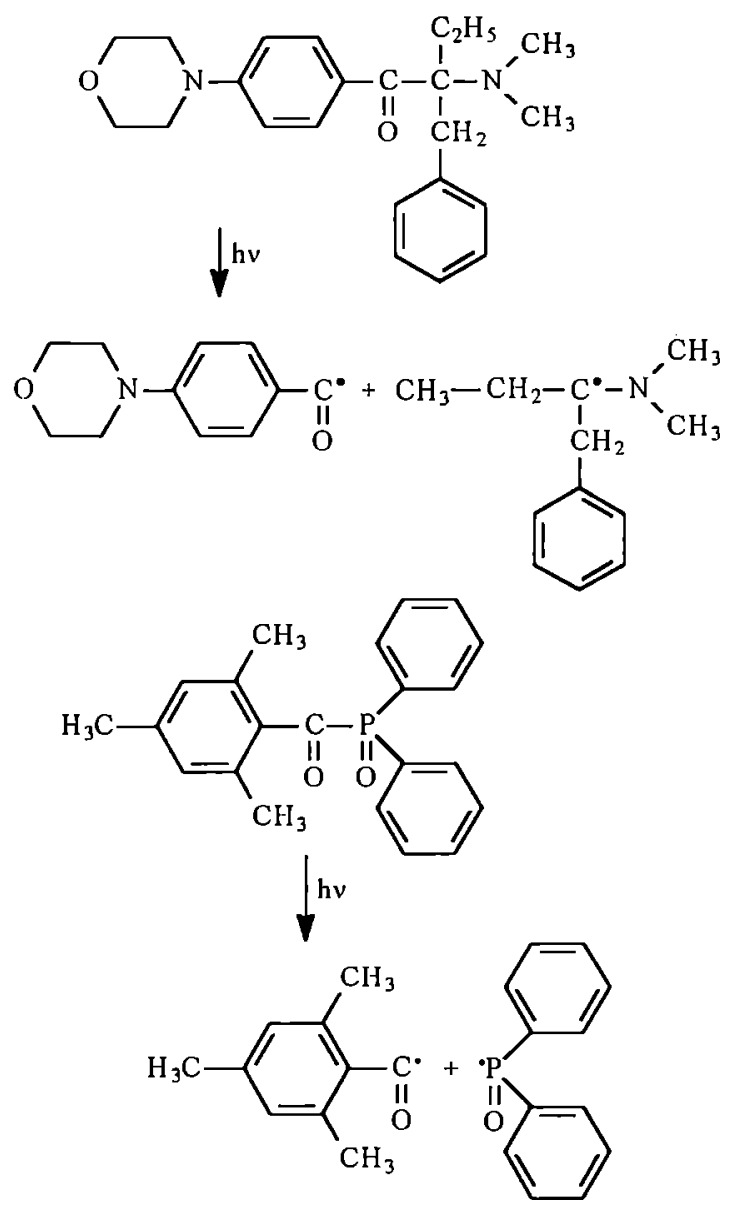

If the photoinitiator decomposes in a unimolecular reaction, the corresponding rate of photoinitiator decomposition $\left(R_{d}\right)$ [mol liter $\left.{ }^{-1} \cdot \mathrm{s}^{-1}\right]$ is first order:

$$
R_{d}=-\frac{\mathrm{d}[\mathrm{I}]}{\mathrm{d} t}=k_{\mathrm{d}}[\mathrm{I}]
$$

Integration of eqn. (6) between $[\mathrm{I}]=[\mathrm{I}]_{0}$ at $t=0$ and [I] at $t$ gives:

$$
[\mathrm{I}]=[\mathrm{I}]_{0} \exp \left(-k_{1} \cdot t\right)
$$

For first-order reactions it is often convenient to integrate between $[\mathrm{I}]=[\mathrm{I}]_{0}$ at $t=0$ and $[\mathrm{I}]=[\mathrm{I}]_{0} / 2$ at $t=t_{1 / 2}$, the half-life of the initiator. The half-life is the time needed for the initial concentration of initiator to decrease to half its initial value. It is related to the initiator photodecomposition rate constant $k_{\text {c }}$ by:

$$
t_{1 / 2}=\frac{\ln 2}{k_{d}}
$$

and is independent of the initial concentration. The conventional criterion for photoinitiator activities is $t_{1 / 2}$.

The $R_{d}$ can be determined by spectroscopy:

$$
R_{d}=\frac{\mathrm{d}[\mathrm{I}]}{\mathrm{d} t}=\frac{\left(\Lambda_{t}-A_{0}\right)}{A_{0}} \frac{[\mathrm{I}]}{t}
$$

where: $A_{0}, A_{t}$ are the absorbances of photoinitiator [I] before and after exposure to the light for time $t$, respectively.

At any moment $R_{d}$ is proportional to the photoinitiator concentration and can be determined by real-time UV spectroscopy [16]:

$$
R_{d t}=\ln \frac{[\mathrm{I}]_{1}}{[\mathrm{I}]_{0}}=-k_{t} t
$$

where: $t$ is the time of irradiation.

The effect caused by excessive concentration of a photoinitiator is well known and has been termed the "inner filter effect", or "screening". This is where light of any or all wavelengths fails to reach the base of a sample because the molecules of the photoinitiator near the surface absorb almost all of it.

The rate of radical production $\left(R_{R}\right.$. $)$ in reaction (1) is given by eqn. (1):

$$
R_{R}=\frac{\mathrm{d}\left[\mathrm{R}^{\cdot}\right]}{\mathrm{d} t}=2 k_{\mathrm{it}} t
$$

since each molecular decomposition produces two radicals.

The initiation of polymerization is followed by addition of the radical $R^{*}\left(R_{1}^{*}\right.$ and/or $\left.R_{2}^{*}\right)$ to a monomer (M):

$$
\mathrm{R}^{\bullet}+\mathrm{M} \stackrel{\mathrm{k}_{\mathrm{i}}}{\longrightarrow} \mathrm{M}^{\bullet}
$$

where: $k_{i}$ is the rate constant of initiation, $M^{*}$ denotes the monomer-ended radical (there is only one monomer in this radical).

The rate of initiation of polymerization $\left(R_{i}\right)[\mathrm{mol} \cdot \mathrm{li}-$ $\left.\operatorname{ter}^{-1} \cdot \mathrm{s}^{-1}\right]$ can be expressed in terms of the rate of radical production as:

$$
R_{i}=\frac{\mathrm{d}\left[\mathrm{R}^{\bullet}\right]}{\mathrm{d} t}=2 \cdot f \cdot k_{\mathrm{i}}[\mathrm{I}]
$$

where: $f$ is the fraction of all radicals generated that react with monomer molecules and is called the initiator efficiency $[11], f \leq 1(0.2-0.7)$.

Most of the kinetics of polymerization ignore the variation of the initiator efficiency with conversion and assume that $f=1$. However, $f$ does vary with the conversion and this variation can be modeled relatively accurately by the expression [22-24]:

$$
f=\frac{k_{s i p}}{k_{s c t r}+k_{r i c}}
$$

where: $k_{s c}$ is the rate constant for radical separation from the cage and $k_{r i c}$ is the rate constant for recombination of the radical $\left(R^{*}\right)$ pair to yield an inert species.

Primary recombination within the monomer cage (cage effect) occurs at less than a molecular diameter during the time of the order of vibration duration $\left(\sim 10^{-13} \mathrm{~s}\right)$ and less than the time between diffusive displacements $\left(\sim 10^{-11} \mathrm{~s}\right)$. The monomer is able to remove the excess kinetic energy by collision and to thermalize the formed radicals within a few molecular diameters. Secondary diffusive recombination within the monomer cage occurs at about one molecular diameter and is rate-controlled by diffusion of two radicals $\left(\sim 10^{-9} \mathrm{~s}\right)$. Other recombinations occur outside the monomer cage. Radicals which escaped the monomer cage can recombine with the radicals generated by another dissociation event or undergo reactions with propagating radi- 
cals. The cage effect, which includes the combination of the first two recombination processes, is very much dependent on monomer viscosity, strength of hydrogen bonding, and mass and geometry of the radicals formed. For dissociation products lighter than the monomer molecules, the cage effect is very high, whereas if the dissociation products are heavier than the monomer, radicals will escape through the walls of the monomer cage. The cage effect simply regenerates the original initiator molecule, but other recombinations can also occur that waste the radicals for polymerization. All photoinitiators suffer cage wastage reactions. Radicals can also undergo other reactions such as rearrangements and fragmentations.

The rate of diffusion of the radical pairs $\left(R^{\circ}\right)$ which escaped the monomer cage should be similar to the rate of diffusion of monomer $\left(k_{\text {diff }(M H)}\right)$ [24], and $k_{\text {sep }}$ can be equated to $k_{\text {diff }(\mathrm{MH})}$ as a reasonable approximation. The activation barrier to the recombination of neighboring radicals is virtually zero [25], and $k_{r c c}$ can be equated to the Arrhenius collision parameter (or pre-exponential factor) and has been assumed to be $10^{10} \mathrm{~mol} \cdot$ liter $^{-1} \cdot \mathrm{s}^{-1}$ $[22,26]$.

The rate of radical production $\left(R_{i}\right)$ is given by:

$$
R_{i}=I_{n} \Phi_{\imath}
$$

where

$$
I_{a}=I_{0} \varepsilon[\mathrm{I}] l
$$

hence

$$
R_{i}=I_{0} \Phi_{d} \varepsilon[\mathrm{I}] l
$$

where: $I_{n}$ is the amount of radiation absorbed, $I_{0}$ - the intensity of incident light, $\Phi_{d}$ - the quantum yield of the photoinitiator photolysis (decomposition) into free radicals, $\varepsilon_{\text {, }}$ (lit $\left.\mathrm{ter}^{-1} \cdot \mathrm{mol}^{-1} \cdot \mathrm{cm}^{-1}\right)$ - the molar extinction coefficient of the photoinitintor, $l$ - the path length, $\mathrm{cm}$.

Quantum yield $\left(\Phi_{d}\right)$ is given by eqn.:

$$
\Phi_{d}=\frac{R_{\mathrm{cl}}}{I_{a}}
$$

where: $I_{a}$ is the amount of light absorbed (number of photons absorbed, measured by chemical actinometers); $R_{d}-$ number of photoinitiator molecules photodecomposed.

Comparison of eqn. (13) with eqn. (17) allows to determine $\Phi_{d}$ by calculation of $k_{d}$ from eqn. $(10)[16,27]$ :

$$
\Phi_{،}=\frac{2 f k_{d}}{I_{0} \varepsilon l}
$$

Photoinitiator efficiency $(f)$ depends on several factors:

- solubility of a given photoinitiator in a monomer (or mixture of monomers). Solubility of some photoinitiators can be increased by addition of small amounts of polar monomers like $N$-vinylcarbazole or 2-hydroxyalkyl methacrylates. However, in such a case, this is a copolymerization reaction to some extent;

- efficient population of the reactive excited singlet
$\left(\mathrm{S}^{*}\right)$ and/or triplet states $\left(\mathrm{T}^{*}\right)$ requires desirable absorptivity characteristics, and a high efficiency of the intersystem crossing (ISC) from $S^{*}$ to $T^{*}$;

- quantum yield $\left(\Phi_{d}\right)$ of the photoinitiator photolysis (decomposition) into free radicals;

- incident light intensity $\left(I_{0}\right)$; for some photoinitiators like Irgacure $369, k_{i}$ was found to increase linearly with $I_{0}\left(>200 \mathrm{~mW} \cdot \mathrm{cm}^{-2}\right)$ [16];

- primary and secondary diffusive recombinations within the monomer cage.

Kinetic model predictions of photoinitiator efficiency $(f)$ require initiation, propagation and termination reactions to be determined ( $c f$. Part II) [28, 29]. By adjusting the rate constant of initiator photodecomposition $\left(k_{1}\right)$, it is possible to vary the relative rates of initiation $\left(k_{i}\right)$ and propagation $\left(k_{p}\right)$. When photoinitiator is irradiated with a high-intensity laser pulse, it decays to radicals prior to any propagation (fast initiation) and $k_{d}$ is very large. When $k_{d}$ is exceedingly small, the situation is reversed and each radical generated will propagate many times and most likely be trapped prior to initiation of any other radicals.

\section{PHOTOINITIATION STEP BY PHOTOINITIATORS ACTING AS DIRECT HYDROGEN-ATOM TRANSFER AGENTS}

Photoinitiators acting as hydrogen-atom transfer agents (I) (eg. benzophenone [1]) under UV/visible radiation are excited to the singlet ${ }^{1} \mathrm{~S}^{*}$ state and by the intersystem crossing (ISC) to the triplet ${ }^{3} \mathrm{~T}^{*}$ states:

$$
\begin{gathered}
I \stackrel{\mathrm{Ix}}{\longrightarrow} \mathrm{I}^{*} \\
\mathrm{I}^{*} \rightarrow{ }^{3} \mathrm{I}^{*}
\end{gathered}
$$

The photoinitiator in the triplet state exists usually as a biradical and can abstract (transfer) directly hydrogen-atom $(\mathrm{H})$ from any hydrogen-atom donor molecules $(\mathrm{DH})$, as solvents, monomers and coinitiators $[1,6]$ :

$$
{ }^{3} \mathrm{I}^{*}+\mathrm{DH} \stackrel{k_{\| \prime}}{\longrightarrow} \mathrm{IH}^{*}+\mathrm{D}^{\bullet}
$$

where: $k_{l i}$ is the rate constant of hydrogen atom transfer from a hydrogen-donor molecule.

Reaction (22) is a bimolecular reaction and $k_{H}$ is therefore a second-order rate constant with the units (concentration $)^{-1} \cdot\left(\right.$ time $^{-1}$. Usually, only donor radicals $\left(D^{*}\right)$ initiate polymerization. Typical photoinitiators of this type are aromatic ketones, eg. benzophenone $[1,6]$, camphorquinone [14,30] and some dyes [2, 10, 12], which can initiate polymerization by direct $\mathrm{H}$-atom abstraction from the monomer $(\mathrm{MH})$ molecule:

$$
{ }^{3} \mathrm{I}^{*}+\mathrm{MH} \stackrel{\mathrm{k}_{\text {IHAm }}}{\longrightarrow} \mathrm{IH}^{*}+\mathrm{M}^{*}
$$

where: $k_{H(M I I)}$ is the rate constant of hydrogen atom abstraction from a monomer molecule.

The monomer radical formed $\left(M^{*}\right)$ can initiate polymerization:

$$
\mathrm{M}^{\bullet}+\mathrm{nMH} \stackrel{k_{\text {ra }}}{\longrightarrow} \mathrm{P}^{\bullet}
$$


where: $k_{i(M H)}$ is the rate constant of initiation by radicals (M -) and $P^{\cdot}$ are propagating radicals.

The monomer radical $\left(\mathrm{M}^{*}\right)$ can also produce a branched polymer because the vinyl end of new polymer radical can react with another growing radical to produce a structure which can grow by adding monomer from the new radical in the interior of a macromolecule.

The initiation efficiencies $\left(f_{H(M H)}\right)$ of photoinitiators reacting by the hydrogen-atom abstraction from the monomer molecules are generally low [1]. In order to increase the initiation efficiency $\left(f_{H(A H)}\right)$ of a given photoinitiator, coinitiators are added. The hydrogen-atom abstraction reaction yields active radicals $\left(A^{\circ}\right)$ :

$$
{ }^{3} \mathrm{I}^{*}+\mathrm{AH} \stackrel{k_{\text {math }}}{\longrightarrow} \mathrm{IH}^{*}+\mathrm{A}^{\cdot}
$$

where: $k_{H(A H)}$ is the rate constant of hydrogen atom transfer from a coinitiator molecule.

Generally, $\mathrm{IH}^{\bullet}$ radicals react with each other to yield dimers, whereas only $A^{*}$ radicals can initiate polymerization:

$$
\begin{gathered}
\mathrm{A}^{\bullet}+\mathrm{MH} \stackrel{\left.\kappa_{i n n l 1}\right)}{\longrightarrow} \mathrm{AMH}^{*} \\
\mathrm{AMH}^{*}+\mathrm{nMH} \rightarrow \mathrm{P}^{\bullet}
\end{gathered}
$$

where: $A M H^{\bullet}$ is the monomer radical, $P^{\bullet}$ is the propagating radical, and $k_{i(A H)}$ is the rate constant of initiation by radicals $\left(A^{\bullet}\right)$.

If monomer can react as $\mathrm{H}$-atom donor, both reactions (24) and (26) are involved in the initiation of polymerization. However, if $f_{H(A H)} \gg f_{H(M H)}$, kinetics consideration are based only on the reaction (26).

In many cases, $\mathrm{H}$-atom abstraction reaction occurs by the electron/proton transfer mechanism (EPT) and kinetics will be different ( $c f$. next section), than in the direct $\mathrm{H}$-atom abstraction (HAA) mechanisms.

If the photoinitiator reacts by a bimolecular reaction the corresponding rate of hydrogen-atom abstraction $\left(R_{H}\right)\left[\mathrm{mol} \cdot\right.$ litre $\left.^{-1} \cdot \mathrm{s}^{-1}\right]$ is first order in initiator and first order in hydrogen-atom donor:

$$
R_{u}=-\frac{\mathrm{d}[\mathrm{I}]}{\mathrm{d} t}=k_{H}\left[{ }^{3} \mathrm{I}^{*}\right][\mathrm{DH}]
$$

Integration of eqn. (28) between $[\mathrm{I}]=[\mathrm{I}]_{0}$ at $t=0$ and [I] at $t$, when [DH] >> [I], with the efficiency of H-atom abstraction assumed to be $f_{I I}=1$ gives:

$$
[\mathrm{I}]=[\mathrm{I}]_{0} \exp \left(-k_{H} t\right)
$$

and $k_{H}$ can be determined from spectroscopical measurements [cf. eqn. (9)].

\section{PHOTOINITIATION STEP BY PHOTOINITIATORS ACTING THROUGH PHOTOINDUCED ELECTRON/PROTON TRANSFER (EPT) MECHANISM}

Photoinduced EPT processes are initiated by the transfer of an electron from, or to, the excited-state photoinitiator (I) to, or from, corresponding ground-state acceptors $(\mathrm{AH})$ or donors $(\mathrm{DH})[13,31]$ :

$$
\begin{aligned}
& \mathrm{I} \stackrel{h v}{\longrightarrow} \mathrm{I}^{*} \\
& \mathrm{I}^{*}+\mathrm{AH} \stackrel{k_{d 1}}{\longrightarrow}\left[\mathrm{I}^{*+} \mathrm{AH}^{\cdot-}\right] \\
& \mathrm{I}^{*}+\mathrm{DH} \stackrel{\mathrm{k}_{1+3}}{\longrightarrow}\left[\mathrm{I}^{--} \mathrm{DH}^{++}\right] \\
& {\left[\mathrm{I}^{+} \mathrm{AH}^{-+}\right] \stackrel{k_{t 11}}{\longrightarrow} \mathrm{IH}^{*}+\mathrm{A}^{*}} \\
& {\left[\mathrm{I}^{-} \mathrm{DH}^{-+}\right] \stackrel{k_{122}}{\longrightarrow} \mathrm{IH}^{*}+\mathrm{D}^{\cdot}}
\end{aligned}
$$

where: $k_{c l}$ and $k_{H}$ are the constants of electron (el) and proton (H) transfers, respectively.

Electron transfer occurs between the I and AH or DH at a rate which depends on their separation. In the EPT processes the observable rate constant $\left(k_{o b s}\right)$ is the sum of $k_{i l}$ and $k_{H i}$ :

$$
k_{a b s}=k_{t^{\prime}}+k_{H}
$$

However, the dominant role is played by $k_{v \prime}$, and under this assumption:

$$
k_{o l s}=k_{t^{\prime}}
$$

$k_{c l}$ is given by:

$$
k_{c t}=\kappa Z \exp \left(-\frac{\Delta G^{\natural}}{R T}\right)
$$

where: $\mathrm{\kappa}$ is the electronic transmission coefficient [32] (negligible), Z the nuclear frequency factor (ca. $6 \cdot 10^{12} \mathrm{~s}^{-1}$ at $\left.25^{\circ} \mathrm{C}\right), \Delta G^{\prime \prime}$ - the free energy of activation given by the Marcus equation.

The Marcus equation for neutral reactants is [33-36]:

$$
\Delta G^{\prime \prime}=\frac{\lambda}{4}\left(1+\frac{\Delta G^{0}}{\lambda}\right)^{2}
$$

where: $\lambda$ is the reorganization energy (factor dependent on the nature of reacting molecules) necessary to reach the transition state of photocxcited photoinitiator $\left(I^{*}\right)$ and of electron donor (DH) [31, 33, 36, 37].

It is given to a first approximation as the sum of two terms [39]:

$$
\lambda=\lambda_{1}+\lambda_{0}
$$

where: $\lambda_{1}$ denotes the inner sphere contribution to the activation energy, mainly the changes in bond lengths during the electron transfer, $\lambda_{0}$ contributes from the outer sphere reorganization mainly from the rcoricntation of the monomer dipoles.

The monomer dependence of $\lambda_{0}$ is expressed by the Pekar factor:

$$
\gamma=\left(\frac{1}{n^{2}}-\frac{1}{\varepsilon_{d}}\right)
$$

where: $n$ is the refractive index and $\varepsilon_{\mathrm{d}}$ is the dielectric constant of the monomer.

Free enthalpy $\left(\Delta G^{0}\right)$ is given by the Rehm-Weller equation [40, 41]: 


$$
\Delta G^{0}=E_{O x}\left(\frac{\mathrm{DH}}{\mathrm{DH}^{++}}\right)-E_{r e d}\left(\frac{\mathrm{I}^{--}}{\mathrm{I}}\right)-E_{l^{*}}-Z e^{2} / \varepsilon \pi
$$

where: $E_{O X}\left(\frac{D H}{D H^{\circ+}}\right)$ is the oxidation potential of the electron donor $(D H)$ molecule, $E_{r e d}\left(\frac{I^{\cdot-}}{I}\right)$ - the reduction potential of electron acceptor (photoinitiator), $E_{\gamma^{*}}$ - the energy of the excited singlet $\left(E_{S^{*}}\right)$ or excited triplet $\left(E_{T^{*}}\right)$ state of photoinitiator (I) from which an electron transfer occurs, $\mathrm{Ze}^{2} / \varepsilon a-$ the Coulombic energy.

This energy is considered negligible to the overall magnitude of $\Delta G^{0}$ :

$$
\Delta G^{0}=E_{O x}\left(\frac{\mathrm{DH}}{\mathrm{DH}^{++}}\right)-E_{r e l}\left(\frac{\mathrm{I}^{*-}}{\mathrm{I}}\right)-E_{l^{*}}
$$

Oxidation $E_{O X}\left(\mathrm{DH} / \mathrm{DH}^{\bullet+}\right)$ and reduction $E_{r e d}\left(I^{\bullet} / \mathrm{I}\right)$ potentials can be easily determined from cyclovoltammetric measurements [42].

For modestly exothermic $\left(\Delta G_{\mathrm{cl}}^{0} \cong-5\right.$ to $\left.-40 \mathrm{kcal} \cdot \mathrm{mol}^{-1}\right)$ bimolecular processes, EPT process is diffusion controlled (i.e. $k_{\mathrm{rl}} \cong k_{\text {diff }} \cong 1 \cdot 10^{10} \mathrm{~mol} \cdot$ liter $^{-1} \cdot \mathrm{s}^{-1}$ ). The energy-wasting reaction is the electron back-transfer:

$$
\begin{aligned}
& {\left[\mathrm{I}^{*+} \mathrm{AH}^{\cdot-}\right] \stackrel{k_{-d_{1}}}{\longrightarrow} \mathrm{I}+\mathrm{AH}} \\
& {\left[\mathrm{I}^{\cdot+} \mathrm{DH}^{\cdot-}\right] \stackrel{k_{-d_{2}}}{\longrightarrow} \mathrm{I}+\mathrm{DH}}
\end{aligned}
$$

where: $k_{-t l}=k_{-d i f f}$ is the rate constant of electron back-transfer.

The energy-wasting reaction is also deactivation (quenching) of the excited singlet and/or triplet states of photoinitiator (I):

$$
\mathrm{I}^{*} \stackrel{k_{\imath}}{\longrightarrow} \mathrm{I}
$$

and photolysis (decomposition) of photoinitiator:

$$
\mathrm{I}^{*} \stackrel{k_{u}}{\longrightarrow} \text { products }
$$

where: $k_{q}$ and $k_{d}$ are the rate constants of quenching and decomposition of photoinitiator, respectively.

Both theoretical [33-35, 42] and empirical [40, 41, 44, 45] relationships are now available to estimate $k_{c l}$ with reasonable accuracy based on the excitation energy of $\mathrm{I}^{*}$ and the ground-state redox properties of photoinitiator (I) and the acceptor (AH) or donor (DH).

The ion-radical pairs generated in the EPT processes are highly reactive intermediates, depending on their nature (contact versus monomer separated complexes), multiplet (singlet versus triplet excited states of photoinitiator) and energies of $\Delta G_{c l}^{0}$.

The formation of ion-radical pairs $\left[\mathrm{I}^{\bullet+} \mathrm{AH}^{{ }^{*-}}\right]$ and $\left[\mathrm{I}^{*-} \mathrm{DH}^{*+}\right]$ occurs by the two-step process: first the formation of the collision complex:

$$
\begin{aligned}
& \mathrm{I}^{*}+\mathrm{AH} \rightarrow\left(\mathrm{I}^{*} \ldots . . \mathrm{AH}\right) \\
& \mathrm{I}^{*}+\mathrm{DH} \rightarrow\left(\mathrm{I}^{*} \ldots . . \mathrm{DH}\right)
\end{aligned}
$$

and next the charge-transfer $(\mathrm{CT})$ complex:

$$
\begin{aligned}
\left(\mathrm{I}^{*} \ldots . . \mathrm{AH}\right) & \rightarrow(\mathrm{I} \ldots \ldots . \mathrm{AH})^{*} \\
\left(\mathrm{I}^{*} \ldots . . . \mathrm{DH}\right) & \rightarrow(\mathrm{I} \ldots . . . \mathrm{DH})^{*}
\end{aligned}
$$

which gives ion-radical pairs:

$$
\begin{aligned}
& (\mathrm{I} \ldots . . \mathrm{AH})^{*} \rightarrow\left[\mathrm{I}^{{ }^{*}} \mathrm{AH}^{{ }^{*-}}\right] \\
& (\mathrm{I} \ldots . . \mathrm{DH})^{*} \rightarrow\left[\mathrm{I}^{{ }^{-}} \mathrm{DH}^{{ }^{*+}}\right]
\end{aligned}
$$

The most common photoinitiating systems are based on aromatic ketones $[1,6,46,47]$, camphorquinone [14, $48-50]$ and dyes $[2,10,12]$ as photoinitiators (I) and amines as electron donors (DH). The $\mathrm{IH}^{*}$ ketyl radicals formed in eqn. (53) are not capable of initiating polymerization, whereas aminyl donor radicals $\left(D^{*}\right)$ are the well known species initiating polymerization [14, 30, 48].

The rate of radical production $\left(D^{\circ}\right)$ from the overall biomolecular EPT reaction:

$$
\begin{gathered}
\mathrm{I}^{*}+\mathrm{DH} \rightarrow \mathrm{IH}^{*}+\mathrm{D}^{*} \\
R_{0^{*}}=\frac{\mathrm{d}\left[\mathrm{D}^{*}\right]}{\mathrm{d} t}=k_{\mathrm{ct}}\left[\mathrm{I}^{*}\right][\mathrm{DH}] \\
R_{0^{*}}=\frac{\mathrm{d}\left[\mathrm{D}^{*}\right]}{\mathrm{d} t}=k_{\mathrm{cl}} I_{a} \cdot \Phi_{1} \cdot[\mathrm{DH}]
\end{gathered}
$$

where: $\Phi_{r^{*}}$ is the quantum yield of the formation of cxcited singlet state $\left(\Phi_{S}.\right)$ or triplet state $\left(\Phi_{T^{*}}\right.$ ) of photoinitiator (I) and $I_{1}$ is the amount of radiation absorbed, given by eqn. (16).

For the triplet state:

$$
\Phi_{\mathrm{T}^{*}}=\Phi_{I S C}
$$

where: $\Phi_{I S C}$ is the quantum yield for the intersystem crossing (ISC) process.

For many photoinitiators $\Phi_{I S C}=1$ and eqn. (55) is simplified to:

$$
R_{D^{*}}=\frac{\mathrm{d}\left[\mathrm{D}^{*}\right]}{\mathrm{d} t}=k_{t i} I_{t}[\mathrm{DH}]
$$

The rate of electron transfer $\left(R_{v l}\right)$ in the EPT process is usually an exponential function of the separation distance between electron acceptor (I) and donor (coinitiator) $(\mathrm{DH})[51-53]$ and is given by:

$$
R_{r i}=\frac{1}{\tau} \exp \left(\frac{r_{0}-r}{v_{0}}\right)
$$

where: $r$ is the photoinitiator-coinitiator (center-to-center) separation, $r_{0}-u s e d$ to paramaterize the distance scale of the electron transfer [determined from the steady-state fluorescence lifetime of photoinitiator $\left.\left(I^{*}\right)\right], v_{0}-$ the wave function of overlap parameter (determined through the time-dependent $I^{*}$ fluorescence quenching), $\tau$ - the fluorescence lifetime of the photoinitiator $\left(I^{*}\right)[15]$.

Inclusion of the donor-acceptor relative diffusion motion into the electron transfer theory has been carried out [54-57]. The solution to this problem is complica- 
ted and involves a partial differential equation for which only a numerical solution is possible. The Inokuti-Hiryama theory [53] cannot be applied to electron/proton transfer in photocrosslinking polymerization because it lacks the proper diffusion motion of I and DH molecules in highly viscous monomers and in the growing crosslinked polymer network (polymer matrix). Electron/proton transfer in highly viscous monomers is therefore improbable, unless diffusion into the complex sphere can take place during the lifetime of the excited state of the photoinitiator.

\section{PROPAGATION STEP}

By definition, a propagation step in a chain reaction is one in which polymer is formed, and the site of the reactive center changes but the number of active centers is not changed [11]. This is strictly true only for nonbranched linear polymerization. In branching chain reactions and crosslinking, the number of active sites may increase during a propagation step. There are two major propagation reactions: addition and chain transfer (atom transfer) reactions. In photocrosslinking polymerization at low $<1-2 \%$ conversion the polymerization rate can be described by linear polymerization kinetics.

Successive monomer additions after the initiation step of reaction (12), can be represented as:

$$
\mathrm{M}^{\bullet}+\mathrm{nM} \rightarrow \mathrm{P}^{\cdot}
$$

Each reaction in the sequence involves the addition of a new monomer molecule to a propagating radical. The rate of propagation $\left(R_{\mu \prime \prime}\right)$ is given by:

$$
R_{p r}=-\frac{\mathrm{d}[\mathrm{M}]}{\mathrm{d} t}=k_{r r}[\mathrm{M}]\left[\mathrm{P}^{\bullet}\right]
$$

where: $\left[P^{\bullet}\right]$ is the sum of the concentrations of all propagating radicals in the system (under assumption that $k_{p r}$ does not depend on the size of $P_{n}^{*}$ :

$$
\left[\mathrm{P}^{\bullet}\right]=\sum_{n=1}^{\infty}\left[\mathrm{P}^{\cdot}\right]_{n}
$$

where: $P_{n}^{*}$ are radicals of chain length $n$.

The propagation rate constant $\left(k_{p r}\right)$ for conventional photopolymerization can be directly determined by using the pulsed-laser polymerization technique [58-62]. The chain length $\left(D P_{0}\right)$ obtained from polymer molecular weight distribution (MWD) is related to the number of propagation events which a radical undergoes to in the time between two laser pulses $\left(t_{0}\right)$ :

$$
D P_{0}=k_{p}[\mathrm{M}] t_{0}
$$

where: $[M]$ is the monomer concentration.

This technique has been applied successfully at low monomer conversion of about $2-3 \%$.

At higher conversions and radical concentrations, carefully calibrated electron paramagnetic resonance (EPR) spectroscopy can be used in some cases to me- asure the concentration of propagating radicals directly [63].

To separate the role of monomer depletion on reaction rate from other effects, it is convenient to define the reduced reaction rate $\left(R_{r u t}\right)$ :

$$
R_{r \mathrm{rut}} \equiv-\frac{\mathrm{d}[\mathrm{M}]}{\mathrm{d} t} \frac{1}{[\mathrm{M}]}=k_{p r}\left[\mathrm{P}^{*}\right]
$$

The propagation rate constant $\left(k_{p r}\right)$ [liter $\left.\cdot \mathrm{mol}^{-1} \cdot \mathrm{s}^{-1}\right]$ is the same for each step of monomer addition to the propagating radical on the assumption that the rate of addition reaction does not depend on the size of the propagating radical. This assumption is only valid in the case of polymerization of monofunctional monomers, however, it is also accepted by many authors in the $\mathrm{ki}$ netics of multifunctional monomers. Values of $k_{p r}$ for most monofunctional monomers are of the order of $10^{2}-10^{3}$ liter $\cdot \mathrm{mol}^{-1} \cdot \mathrm{s}^{-1}$. Reaction (59) is a bimolecular reaction with units of (concentration) ${ }^{-1} \cdot(\text { time })^{-1}$. The local concentration of the monomer is reduced by the propagation. However, monomer diffusion from regions rich in the monomer substantially affects the monomer distribution in the course of polymerization.

Kinetic model predictions of propagation (and polymerization) can be based on the ability of all species in the reaction to move [28]. Photoinitiator, monomer, and polymer may move and diffuse with the only constraints that all bonds must be preserved and movement must occur from an occupied site to an unoccupied site. Mobility increases as void sites increase and the bonding between sites decreases. For example, a monomer functional group that is attached to only one other site moves much more easily than does a polymer site that is attached to two sites along the polymer chain and also bonded to the monomer.

\section{TERMINATION STEPS}

Propagation of polymerization is terminated by the mutual annihilation (termination by combination) of two propagating radicals:

$$
\mathrm{P}_{n}^{\cdot}+\mathrm{P}_{m}^{\cdot} \stackrel{k_{r+1}}{\longrightarrow} \mathrm{P}_{n+m} \text { (dead polymer) }
$$

and/or by radicals from the initiator at higher initiator concentrations (primary radical termination):

$$
\mathrm{P}_{\mathrm{n}}^{*}+\mathrm{I}^{\cdot} \stackrel{k_{w 2}}{\longrightarrow} \text { dead polymer }
$$

where: $I^{\bullet}$ is the initiator radical, and $k_{l c 1}$ and $k_{l c 2}$ Iliter $\cdot$ mol $^{-1}$ $\left.\cdot s^{-1}\right]$ are termination rate constants.

The rates of these reactions are additive, because both reactions are bimolecular and have second order rate constants:

$$
k_{t c}=k_{t c l}+k_{t c 2}
$$

The termination rate $\left(R_{t c}\right)$ by combination reactions is given by:

$$
R_{t c 1}=2 k_{t c 1}\left[\mathrm{P}^{\cdot}\right]^{2}
$$


and/or

$$
R_{t c 2}=2 k_{t c 2}\left[\mathrm{P}^{*}\right]\left[\mathrm{I}^{*}\right]
$$

and the overall termination rate:

$$
R_{t c}=R_{l c 1}+R_{t c 2}
$$

However, termination of polymerization by radicals from the photodecomposition of photoinitiator can be considered negligible at high conversions. Radicals will be unable to quickly react away from their initial positions and so they will be susceptible to recombining into inactive species which failed to initiate any polymerization. Then, eqn. (67) is:

$$
R_{t c}=2 k_{t c}\left[\mathrm{P}^{\bullet}\right]^{2}
$$

Typical termination rate constants for conventional polymerization of monofunctional monomers are of the order $10^{6}-10^{8}$ liter $\cdot \mathrm{mol}^{-1} \cdot \mathrm{s}^{-1}$ [11]. These rate constants are much greater than propagation rate constants, but polymerization still occurs because the overall rate of polymerization $\left(k_{p}\right)$ is proportional to $k_{p r}$ and inversely proportional to $k_{t}^{1 / 2}$ ( $c f$. next section).

Propagation of polymerization can be also terminated by two other reactions: as disproportionation reaction, with $R_{t d}$ :

$$
R_{l d}=2 k_{t d}\left[\mathrm{P}^{*}\right]^{2}
$$

where: $k_{t u}$ is the termination rate constant by disproportionation reaction and by trapping of propagation radicals in the polymer crosslinking net (cf. next section). It is generally accepted that the most propagating radicals in free-radical polymerization of monofunctional monomers terminate predominantly or entirely by combination. The overall termination rate $k_{t}$ is given by:

$$
k_{l}=k_{t c}=k_{t t}
$$

Radical combination and disproportionation reactions in principle have two steps: rotation of the radicals to adopt an appropriate orientation, and the actual bond formation. In monomers viscous enough to slow down rotations within the monomer cage, rotation can be the rate-determining step, in which case $k_{t c} / k_{t l}$ becomes dependent on monomer viscosity.

The termination by disproportionation will be more important for tertiary than for secondary macroradicals. The tertiary macroradicals have more $\beta$-hydrogens available for transfer during disproportionation, and direct coupling of tertiary radicals is more hindered sterically. Thus poly(methyl methacrylate) radicals terminate by combination and disproportion, while combination termination is the only mode observed in polystyryl radical termination. The $k_{t c} / k_{t d}$ ratio (where $k_{t c}$ and $k_{t t}$ are termination rate constants by combination and disproportionation, respectively) in polymers which terminate by both processes is temperature sensitive with higher temperatures promoting disproportionation.

Important note [11]: Papers published in the United States and in the United Kingdom use different conventions for termination rates $\left(R_{t}\right)$ and termination rate constants $\left(k_{1}\right)$. This paper follows the American convention. In this case $k_{l c}$ and $k_{t l}$ are defined by:

$$
R_{l}=-\frac{\mathrm{d}\left[\mathrm{P}^{*}\right]}{\mathrm{d} t}=2 k_{t c}\left[\mathrm{P}^{\cdot}\right]^{2}+2 k_{t t}\left[\mathrm{P}^{*}\right]^{2}
$$

It follows that:

$$
\frac{\mathrm{d}[\text { polymer] }}{\mathrm{d} t}=k_{t c}\left[\mathrm{P}^{\bullet}\right]^{2}+2 k_{t, l}\left[\mathrm{P}^{\bullet}\right]^{2}
$$

since a single termination reaction produces one polymer molecule by combination or two if disproportionation occurs:

The British convention:

$$
R_{t}=-\frac{\mathrm{d}\left[\mathrm{P}^{*}\right]}{\mathrm{d} t}=k_{t i}\left[\mathrm{P}^{*}\right]^{2}+k_{\mathrm{t}}\left[\mathrm{P}^{*}\right]^{2}
$$

and, hence:

$$
\frac{\mathrm{d}[\text { polymer }]}{\mathrm{d} t}=\frac{k_{t c}\left[\mathrm{P}^{\bullet}\right]^{2}}{2}+k_{t t}\left[\mathrm{P}^{\bullet}\right]^{2}
$$

These two conventions cannot be mixed, because the termination rate constants quoted by the American convention will be exactly half those measured by the British system.

\section{TERMINATION BY TRAPPING RADICALS IN THE CROSSLINKED NETWORKS}

Propagation of polymerization is also terminated by trapping the growing radicals in the crosslinked network (polymer matrix) almost indefinitely [64-73]. The observed decrease in bimolecular (termination by combination) rate constant $\left(k_{t c}\right)$ during photocrosslinking polymerization is the result that propagating radicals are trapped in crosslinked polymer regions from the beginning of the reaction. They can migrate and encounter other radicals only by chain propagation or chain transfer, and not by free diffusion, as is the case in the liquid phase in linear polymerization. The presence of trapped radicals indicates the existence of inhomogeneous regions which are more crosslinked than are other regions in a polymer matrix [74]. This causes the existence of propagating radicals with different termination tendencies: bimolecular $(b)$ second-order termination by combination:

$$
R_{t b}=2 k_{t b}\left[\mathrm{P}^{\bullet}\right]^{2}
$$

where: $R_{t b}=R_{t c}$ and $k_{t b}=k_{t c}$.

and a monomolecular $(m)$ first-order process involving only one propagating trapped radical:

$$
R_{t m}=k_{t m}\left[\mathrm{P}^{\bullet}\right]
$$

where: $R_{t b}$ and $R_{t m}$ are bimolecular and monomolecular termination rates, respectively; $k_{l b}$ and $k_{l m}$ are bimolecular and monomolecular termination rate constants.

For overall (mixed) termination, the termination rate $\left(R_{\text {lmix }}\right)$ is: 


$$
R_{t m i x}=R_{l b}+R_{l ! \prime}
$$

After combination and subsequent integration of eqn. (60), (77) and (79) three models are obtained for the different termination mechanisms [71, 72]:

Monomolecular termination (model I):

$$
-\ln (1-p)=\frac{k_{\mu}}{k_{t m}}\left[P^{*}\right]_{l}\left[1-\exp \left(-k_{t m}\right) t\right]
$$

Bimolecular termination (model II):

$$
-\ln (1-p)=\frac{1}{2} \frac{k_{p}}{k_{t b}} \ln \left(1+2\left[P^{*}\right], k_{t b} t\right)
$$

Mixed termination (model III):

$$
-\ln (1-p)=\frac{1}{2} \frac{k_{p}}{k_{t b}} \ln \left[1+2\left[P^{\bullet}\right]_{t} \frac{k_{l t}}{k_{t m}}\left(1-\exp \left(-k_{t m} t\right)\right)\right]
$$

where: $\left[P^{\cdot}\right]$, is the concentration of propagating radicals after irradiation time $t$ and $p$ is the degree of double bond conversion.

The results obtained show that the first order reaction is an important termination in the crosslinking photopolymerization even at low degrees of monomer conversion [71, 72]. Under irradiation at the early stages the bimolecular reaction is dominated by reactions involving newly formed mobile short-chain radicals able to diffuse and to react with themselves or with macroradicals connected to the network. Whereas in the dark, formation of short chain-radicals is abruptly stopped which immediately affects the bimolecular termination [72].

The contemporary presence of different radicals and the fact that their reactivity might be modified by the polymer matrix (crosslinked networks) environment complicate the system under study [75], especially in photopolymerized multifunctional acrylate monomers [76-79]. ESR (electron spin resonance) TR-ESR (time-resolved electron spin resonance) and ENDOR (electron nuclear double resonance) analysis of radicals produced during photopolymerization of multifunctional methacrylates have been modeled [80-84]. Within these frameworks, the conventional rate constant of trapped radical decay $\left(k_{t r}\right)$ is replaced by the time dependent specific reaction rate $\left[k_{l r}(t)\right]$ :

$$
k_{r r}(t)=B t^{u-1} \quad 0<\alpha<1
$$

where: $B$ is a constant whereas parameter a measures the dispersion of activation energy of decay reaction [85].

For $\alpha>1, k_{p}$ is no longer time dependent and a conventional kinetic laws applies. In the case of second-order kinetics the integrated rate equation with the time-dependent rate constant $k_{l r}(t)$ is given as

$$
\left[P^{\bullet}\right]^{-1}-\left[P^{\bullet}\right]_{0}^{-1}=(B / \alpha) t^{a}
$$

Both $\alpha$ and $B$ parameters determine the effective rate of radicals decay. $B$-values are sensitive to conversion degree, and likewise $\alpha$, both increase with temperature.
At $\alpha \cong 1$ radical decay occurs according to a classical bimolecular termination mechanism.

\section{CHAIN TRANSFER REACTIONS}

In many free-radical polymerizations, the growth of propagating radical is terminated by the transfer of an atom to the macroradical from photoinitiator, monomer, polymer or other species in the reaction mixture, c.g. different additives in an industrial photocuring. In general, for any transfer agent (TH) [11]:

$$
\mathrm{P}^{*}+\mathrm{TH} \stackrel{\boldsymbol{k}_{*}}{\longrightarrow} \mathrm{PH}+\mathrm{T}^{*}
$$

where: $k_{l r}$ is the transfer rate constant.

The rate of transfer $\left(R_{t r}\right)$ is:

$$
R_{t r}=k_{t r}\left[\mathrm{P}^{\cdot}\right][\mathrm{TH}]
$$

assuming as usual that the transfer rate constant $k_{\text {ir }}$ is the same for all monomer-ended radicals and taking $\left[\mathrm{P}^{*}\right]$ to be the concentration of all such species. The magnitude of $k_{l}$. will depend on the nature of $\mathrm{P}^{\cdot}$ and $\mathrm{TH}$ as well as the reaction temperature. The new radical $\mathrm{T}^{\bullet}$ can reinitiate polymerization:

$$
\mathrm{T}^{\bullet}+\mathrm{M} \stackrel{k,}{\longrightarrow} \mathrm{TM}^{\bullet}
$$

where: $k_{r}$ is the rate constant for addition of a particular monomer $(M)$ to $P^{\cdot}$ radical.

Monomer chain transfer constants are generally less than $10^{-4}$ liter $\cdot \mathrm{mol}^{-1} \cdot \mathrm{s}^{-1}$ [11].

If chain transfer is a significant mechanism that leads to termination, then the rate of termination $\left(R_{i}\right)$ is:

$$
R_{t} \propto k_{p}[\mathrm{M}]+R_{t r}
$$

Chain transfer to polymer yields a radical on the polymer chain. Polymerization of monomer from this site produces a polymer with a long branch. Transfer to polymer is important with very reactive radicals and in monomers in which significant stabilization is absent. It is also most significant in high conversion reactions where the concentration of polymer in the system is relatively high. This is a very common process in the crosslinking polymerization.

\section{TERMINATION OF POLYMERIZATION BY OXYGEN}

Both initiation and propagation of polymerization are terminated (inhibited, scavenged) by oxygen, giving peroxide radicals $\left(\mathrm{POO}^{\circ}\right)$ [30, 86-91]:

$$
\mathrm{P}^{\bullet}+\mathrm{O}_{2} \rightarrow \mathrm{POO}^{\bullet}
$$

which are always present in polymerized systems. The oxygen level must be reduced to $1 / 1000$ of the initial value before the initiation of polymerization can compete successfully [92].

The rate of oxygen inhibition $\left(R_{i m l}\right)\left[\mathrm{mol} \cdot\right.$ liter $\left.^{-1} \cdot \mathrm{s}^{-1}\right]$ is given by: 


$$
R_{\text {inl }}=k_{\text {iul }}\left[\mathrm{P}^{\cdot}\right]\left[\mathrm{O}_{2}\right]
$$

where: $k_{\text {int }}$ is the rate constant of oxygen inhibition [liter . $\left.\mathrm{mol}^{-1} \cdot \mathrm{s}^{-1}\right]$.

Rate constants for the reaction of carbon-centered radicals with oxygen are very fast, generally, $k_{\text {inh }}>10^{9} \mathrm{li}-$ ter $\cdot \mathrm{mol}^{-1} \cdot \mathrm{s}^{-1}$ [93-95]. Peroxy radicals (POO ${ }^{\circ}$ ) are generally considered to be unreactive to start a polymerization but they can participate in radical recombination reactions:

$$
\begin{gathered}
\mathrm{POO}^{*}+\mathrm{P}^{\bullet} \rightarrow \text { POOP } \\
\mathrm{POO}^{*}+\mathrm{PO}^{*} \rightarrow \mathrm{POP}+\mathrm{O}_{2} \\
\mathrm{POO}^{*}+\mathrm{POO}^{*} \rightarrow \mathrm{POOP}+\mathrm{O}_{2}
\end{gathered}
$$

and/or abstract hydrogen-atom from a monomer $(\mathrm{MH})$ or a polymer $(\mathrm{PH})$ molecule giving hydroperoxide groups and new potential monomer radical $\left(\mathrm{M}^{\circ}\right)$ for initiation of a new propagating chain:

$$
\begin{gathered}
\mathrm{POO}^{\bullet}+\mathrm{MH} \rightarrow \mathrm{POOH}+\mathrm{M}^{\bullet} \\
\mathrm{POO}^{\bullet}+\mathrm{PH} \rightarrow \mathrm{POOH}+\mathrm{P}^{\bullet}
\end{gathered}
$$

The rate of hydroperoxide group formation $\left(R_{\mathrm{OOH}}\right)$ $\left[\mathrm{mol} \cdot\right.$ liter $\left.^{-1} \cdot \mathrm{s}^{-1}\right]$ is given by:

$$
R_{\mathrm{OOH}}=k_{\mathrm{OOH}}\left[\mathrm{POO}^{*}\right][\mathrm{MH}]
$$

where: $k_{\mathrm{OOH}}$ is the rate of hydroperoxide group formation [liter $\left.\cdot \mathrm{mol}^{-1} \cdot \mathrm{s}^{-1}\right]\left(k_{\mathrm{OOH}}=0.24\right.$ liter $\cdot \mathrm{mol}^{-1} \cdot \mathrm{s}^{-1}$ for reaction of POO ${ }^{\circ}$ radicals with monomeric methyl methacrylate) [96].

Polymer radicals $\left(\mathrm{P}^{*}\right)$ react with monomer (methyl methacrylate) with a rate constant of $515 \mathrm{liter} \cdot \mathrm{mol}^{-1} \cdot \mathrm{s}^{-1}$ [96]. This difference implies that $\mathrm{POO}^{*}$ radicals are nearly 2000 times less reactive than $\mathrm{P}^{\circ}$ radicals.

In the photocrosslinking polymerization the rate of inhibition $\left(R_{\text {inth }}\right)$ is dependent on oxygen diffusion $\left(D_{O X}\right)$ in a polymerized matrix [97]. The rate of oxygen inhibition is expressed as:

$$
R_{i t t h}=\frac{\mathrm{d}\left[\mathrm{O}_{2}\right]}{\mathrm{d} t}=k_{D o x}\left(\frac{\left.\partial \mathrm{O}_{2}\right]}{\partial \mathrm{x}^{2}}\right)-k_{\text {itth }}\left[\mathrm{O}_{2}\right]\left[\mathrm{P}^{*}\right]
$$

where: $k_{\text {Dor }}\left[\mathrm{cm}^{2} \cdot \mathrm{s}^{-1}\right]$ the oxygen diffusion rate constant, which vories in a polymer matrix from $10^{-7}$ to $10^{-8} \mathrm{~cm}^{2} \cdot \mathrm{s}^{-1}$.

The oxygen diffusion is higher than that of monomer, thus polymerization is inhibited in unprotected polymerizing system from air. Oxygen solubility in a polymer matrix or a viscous organic liquid at room temperature is $3 \cdot 10^{-6} \mathrm{~mol} \cdot \mathrm{cm}^{-3}(90 \mathrm{ppm})[98,99]$. The ability of oxygen to diffuse is related to its mobility through the polymerizing medium and hence to the medium viscosity [89]. Oxygen diffusion is most efficient in the top layer and its effect ceases, under normal photopolymerization light intensities and photoinitiator systems concentrations, when the depth of the sample exceeds $10 \mu \mathrm{m}$.

The inhibited surface by oxygen appears as an uncured (wet, "tacky" surface) layer thickness $X_{\mathrm{O}_{2}}$ on the surface of the partially photopolymerized sample, whose thickness is dependent on the incident light intensity $\left(I_{0}\right)$, the exposure time $(t)$, and photoinitiator concentration ([I]) according to the following equation [100]:

$$
X_{O_{2}}=\frac{\Lambda+{ }_{t}^{B}}{I_{0}}[\mathrm{I}]
$$

where: $A$ and $B$ are empirical constants.

Inhibition of polymerization by oxygen can have deleterious effects on such properties as hardness and impact resistance of photocured polymer.

End note: This article has been written by Dr. Julita Jakubiak, Head of the Joint Project "Mechanisms, kinetics and applications of photopolymerization initiated by visible light photoinitiators", supervised by Prof. J. F. Rabek and Prof. J. P. Fouassier. Dr J. Jakubiak spent one year (1998/1999) as post-doc researcher at Polymer Research Group, Department of Dental Biomaterial Science, Karolinskn Institute, The Royal Academy of Medicine, Stockholm, Szueden (directed by Prof. J. F. Rabck) and one year (1999/2000) as post-doc researcher at Laboratoire de Photochimie Generale, CNRS, University of Mulhouse, France (directed by Prof. J. P. Fouassier).

\section{REFERENCES}

[1] Rabek J. F.: "Mechanism of Photophysical Processes and Photochemical Reactions in Polymers", Wiley, London 1987. [2] Dietliker K. K. in: "Chemistry \& Technology of UV/VB Formulations for Coatings", Inks \& Paints, Vol. III, "Photoinitiators for Free Radical and Cationic Polymerization" (Ed., Oldring P. K. T.), SITA Technology Ltd., London 1991, p. 228. [3] Monroe B. M., Weed G. C.: Chem. Rev. 1993, 93, 435. [4] Rabek J. F. in: "Radiation Curing in Polymer Science and Technology", Vol. I. "Fundamentals and Methods" (Eds., Fouassier J. P., Rabek J. F.), Elsevier Applied Science, London 1993, p. 453. [5] Fouassier J. P., Rabek J. F. (Eds.): "Radiation Curing in Polymer Science and Technology", Vol. II, "Photoinitiating Systems", Elsevier Applied Science, London 1993. [6] Fouassier J. P.: "Process in Photoreactive Polymers" (Eds., Krongauz V. V., Trifunac A. D.), Chapman and Hall, New York 1955, p. 59. [7] Yamaoka T., Naitoh K. in: "Process in Photoreactive Polymers" (Eds., Krongauz V. V., Trifunac A. D.), Chapman and Hall, New York 1955, p. 111. [8] Krongauz V. V.: "Process in Photoreactive Polymers" (Eds., Krongauz V. V., Trifunac A. D.), Chapman and Hall, New York 1955, p. 185. [9] Fouassier J. P.: "Photoinitiation, Photopolymerization and Photocuring: Fundamentals and Applications", Hanser Publ., Munich 1995. [10] Necker D. C., Jager W.: "Photoinitiation for Polymerization: UV \& EB at the Millenium", Wiley, Chichester 1998.

[11] Rudin A.: "The Elements of Polymer Science and 
Engineering", 2nd ed., Academic Press, San Diego 1999. [12] Jakubiak J., Rabek J. F.: Polimery 1999, 44, 447. [13] Lindén L. A., Pączkowski J., Rabek J. F., Wrzyszczyński A.: Polimery 1999, 44, 161. [14] Rabek J. F., Fouassier J. P., Lindén L. Å., Nie J., Andrzejewska E., Jakubiak J., Pączkowski., Wrzyszczyński A., Sionkowska A.: "Photosensitive Systems for Photopolymerization Reactions" (Ed., Fouassier J. P.), Research Trends in Photochem Photobiol 1999, 5, 51. [15] Moad G., Solomon D. H.: "The Chemistry of Free Radical Polymerization", Pergamon, London 1995. [16] Decker C.: Proc. Rad. Tech. Europe '93, Mediterraneo 1993, p. 2. [17] Norrish R. G. W., Searby M. H.: Proc. Roy. Soc., London Ser. A 1956, 237. [18] Desobry V., Dietliker K., Hüsler R., Misev L., Rembold M., Rist G., Rutsch W.: "Radiation Curing of Polymeric Materials" (ACS Symp. Ser. No. 417), American Chemical Society, Washington, DC 1990, p. 92. [19] Decker C. in: "Processes in Photoreactive Polymers" (Eds., Krongauz V. V., Trifunac A. D.), Chapman and Hall, New York 1995, p. 34. [20] Dietliker K., Leppard D., Jung T., Köhler M., Valet A., Kolczak U., Rzadek P., Rist G.: Proc. Conf. Rad. Tech. '97 Asia, Yokohama, Japan 1997, p. 292.

[21] Jacobi M., Henne A., Boettcher A.: Polym. Paint Colour J. 1985, 175, 636. [22] Sack R., Schulz G. V., Meyerhoff G.: Macromolecules 1988, 21, 3345. [23] Zhu S., Tian Y., Hamielec A. E., Eaton D. R.: Polymer 1990, 31, 154. [24] Russel G. T., Napper D. H., Gilbert R. G.: Macromolecules 1988, 21, 2141. [25] Flory P. J.: "Principles of Polymer Chemistry", Cornell University Press, Ithaca, NY 1953, Ch. 4. [26] Cook W. D.: J. Polym. Sci., Polym. Chem. Ed. 1993, 31, 1053. [27] Decker C.: J. Polym. Sci., Polym. Chem. Ed. 1992, 30, 913. [28] Bowman C. N., Peppas N. A.: Chem. Eng. Sci. 1992, 47, 1411. [29] Goodner M. D., Bowman C. N. in: "Solvent-Free Polymerizations and Processes" (Eds., Lond T. E., Hunt M. O.), ACS Symposium Series, No 713, American Chemical Society, Washington, DC 1998. [30] Nie J., Lindén L. A., Rabek J. F., Fouassier J. P., Morlet-Savary F., Ścigalski F., Wrzyszczyński A., Andrzejewska E.: Acta. Polym. 1998, 49, 145.

[31] Kavarnos G. J., Turro N. J.: Chent. Rev. 1986, 86, 401. [32] Newton M. D., Sutin N.: Ann. Rev. Phys. Chem. 1984, 35, 437. [33] Marcus R. A.: J. Chem. Phys. 1956, 24, 966, 979. [34] Marcus R. A.: Disc. Faradny Soc. 1960, 29, 21. [35] Marcus R. A.: J. Chem. Phys. 1965, 43, 679. [36] Marcus R. A.: J. Phys. Chem. 1968, 72, 891. [37] Bolton J. B., Archer M. D.: Adv. Chem. Ser. 1991, 29, 7. [38] Kavarnos G. J.: "Fundamental of Photoinduced Electron Transfer", VCH, Weinheim 1993. [39] Marcus R. A.: Ann. Rev. Phys. Chem. 1964, 15, 155. [40] Rehm D., Weller A.: Ber Bunsen Ges. Phys. Chem. 1969, 73, 834.

[41] Rehm D., Weller A.: Isr. J. Chem. 1970, 8, 259. [42] Wilford J. H., Archer M. D., Bolton J. R., Ho T. F., Schmidt J. A., Weedon A. C.: J. Phys. Chom. 1985, 89, 5395. [43] Scandola F., Balzani V., Schuster G. B.: J. Am. Chen. Soc. 1981, 103, 2519. [44] Knibbe H., Rehm D., Weller A.: Ber. Bunsen Ges. Phys. Chem. 1969, 73, 839. [45] Rehm D., Weller A.: Z. Phys. Chem. 1970, 69, 183.
[46] Cohen S. G., Parola A., Persons G. H.: Chem. Rev 1973, 73, 141. [47] Hoshino M., Shizuka H. in: "Radiation Curing in Polymer Science and Technology", Vol II, Photoinitiating (Eds., Fouassier J. P., Rabek J. F.), Elsevier Applied Science, London 1993, p. 637. [48] Cook W. D.: Polymer 1992, 33, 600. [49] Mateo J. L., Bosch P., Lozano A. E.: Macromolecules 1994, 27, 7794. [50] Kucybala Z., Pietrzak M., Pączkowski J., Lindén L. A., Rabek J. F.: Polymer 1996, 37, 4585.

[51] Dexter D. L.: J. Chem. Phys. 1953, 21, 836. [52] Kestner N. R.: Logan J., Jortner J.: J. Phys. Chem. 1974, 78, 2148. [53] Inokuti M., Hirayama F.: J. Chem. Phys. 1965, 43, 1978. [54] Blumen A.: J. Chem1. Phys. 1980, 72, 2632. [55] Allinger K., Blumen A.: J. Chem. Phys. 1981, 75, 2762. [56] Huddleston R. K., Miller J. R.: J. Phys. Chem. 1983, 86, 200. [57] Sipp B., Voltz R.: J. Cliem. Phys. 1983, 79, 434. [58] Hutchinson R. A., Aronson M. T., Richards J. R.: Macromolecules 1993, 26, 6410. [59] O'Driscoll K. F., Kuindresma M. E.: Macromol. Theory Simul. 1994, 3, 469. [60] Beuermann S., Paquet D. A., McMinn J. H. Jr., Hutchinson R. A.: Macromolecules 1996, 29, 4206.

[61] Olaj O. F., Bitai I., Hinkelmann F.: Makromol. Chem. 1987, 188, 1689. [62] Hutchinson R. A., Beuermann S., Paquet D. A., McMinn J. H.: Macromolecules 1997, 30, 3490. [63] Carswell T. G., Hill D. J. T., Hunter D. S., Pomery J. H., O'Donnell J. H., Winzor C. L.: Europ. Polym. J. 1990, 26, 541. [64] Scheren P. A. G. M., Russell G. T., Sangster D. F., Gilbert R. G., German A. L.: Macromolecules 1995, 28, 3637. [65] Kloosterboer J. G., Lippits G. J.: J. Imag. Sci. 1986, 30, 177. [66] Kloosterboer J. G., Lijten G. F. C. M., Greidanus F. J. A. M.: Polym. Commun. 1986, 27, 268. [67] Kloosterboer J. G.: Adv. Polym. Sci. 1988, 84, 1. [68] Ottavami M. F., Fiorini A., Mason P. N., Corvaja C.: Dent. Mater. 1992, 8, 118. [69] Fujimori Y., Kaneko T., Kaku T., Ypsiko N., Nishida H., Tsuchida E.: Polym. Adv. Teclnol. 1992, 3, 37. [70] Selli E., Oliva C.: Makromol. Chem. Phys. 1996, 187, 497.

[71] Andrzejewska E., Bogacki M. B.: Makromol. Chem. Phys. 1997, 198, 1649. [72] Andrzejewska E., Bogacki M. B., Andrzejewski M.: Proc. Conf. Rad. Tech. '99, Berlin, Germany 1999, p. 779. [73] Bellobono I. R., Selli E., Righetto L., Rafelini P., Trevisan L.: Makromol. Chent. 1989, 190, 1945. [74] Kurdikar D. L., Peppas N. A.: Macromolecules 1994, 27, 4084. [75] Tonge M. P., Pace R. J., Gilbert R. G.: Makromol. Chem. Phys. 1994, 195, 3159. [76] Bellobono I. R., Olivia C., Morelli R., Selli E., Ponti A.: J. Chem. Soc. Faraday Trans. 1990, 86, 3273. [77] Oliva C., Selli E., Ponti A., Bellobono I. R., Morelli R.: J. Phys. Organ. Chem. 1992, 5, 55. [78] Selli E., Oliva C., Galbiatti M., Bellobono I. R.: J. Chem. Soc., Faraday Trans. 1992, 88, 1391. [79] Selli E., Oliva C., Giussani A.: J. Chem. Soc., Faraday Trans. 1994, 90, 1967. [80] Oliva C., Selli E., Di Blas S., Termignone G.: J. Chem. Soc. Perkin Trans. 1995, 2, 2133.

[81] Selli E., Oliva C.: Makromol. Chem. Phys. 1995, 196, 4129. [82] Rist G., Borer A., Dietliker K., Desorby V., Fouassier J. P., Ruhlmabb D.: Macronolecules 1992, 
25, 4182. [83] Kolczak U., Rist G., Dietliker K., Wirz J.: J. Am. Chem. Soc. 1996, 118, 6477. [84] Dietliker K., Kunz M., Wolf J. P., Gatlik I., Neschadin D., Gescheid G., Rzadek P., Rist G.: Proc. Conf. Rad. Tech. '99, Berlin, Germany 1999, p. 379. [85] Plonka A.: Radiat. Phys. Chem. 1991, 37, 555. [86] Che K. K.: Europ. Polym. J. 1985, 21, 29. [87] Boutevin B., Pietrasanta Y., Sarraf L., Snoussi H.: Europ. Polym. J. 1988, 24, 539. [88] Decker C., Moussa K.: Makromol. Chem. 1988, 189, 2381. [89] Decker C., Moussa K.: Proc. Conf. Rad. Tech. '88 Europe, Florence, Italy 1989, p. 231. [90] Andrzejewska E., Lindén L. A., Rabek J. F.: Makromol. Chem. Phys. 1998, 199, 441.

[91] Nie J., Andrzejewska E., Rabek J. F., Lindén L. §., Fouassier J. P., Pączkowski J., Ścigalski F., Wrzyszczyński A.: Makromol. Chem. Phys. 1999, 200, 1692. [92] Kunz M., Strobel R., Grysau D.: Proc. Conf. Rad. Tech. '97, Europe, Lyon, France, 1997, p. 291. [93] Maillard B.,
Ingold K. U., Scaiano J. C.: J. Am. Chem. Soc. 1983, 105, 5095. [94] Kloosterboer J. G., Lijten G. F. C. M., Zegers C. P. G.: Polym. Mater. Sci. Eng. Proc. 1989, 60, 122. [95] Neta P., Huie R. E., Ross A. B.: J. Chem. Phys., Ref. Data 1990, 19, 413. [96] Kerber V., Serini V.: Makromol. Chem. 1970, 1, 140. [97] Krongauz V. V. in: "Process in Photoreactive Polymers" (Eds., Krongauz V. V., Trifunac A. D.), Chapman and Hall, New York 1995, p. 185. [98] Moisan J. Y. in: "Polymer Permability" (Ed., Comin J.), Elsevier, London 1988, p. 127. [99] Chu D. Y., Thomas J. K., Kuczyński J.: Macromolecules 1988, 21, 2094. [100] Ors J. A., Nunez I. M., Falanga L. A. in: "Crosslinked Polymers, Chemistry, Properties and Applications" (Eds., Dickie R. A., Labana S. S., Bauer R. S.), ACS Symposium Series, No. 367, American Chemical Society, Washington, DC, 1988, p. 439. 